\title{
Identification of Model Parameters of Vaporized Hydrogen Peroxide Decomposition Flux on Building Materials for Computational Fluid Dynamics
}

\author{
Kazuhide Ito*, Sung-Jun Yoo, Hirofumi Horata \\ Interdisciplinary Graduate School of Engineering Science, Kyushu University, Fukuoka, Japan \\ Email: "ito@kyudai.jp
}

Received 4 December 2015; accepted 22 February 2016; published 25 February 2016

Copyright (C) 2016 by authors and Scientific Research Publishing Inc.

This work is licensed under the Creative Commons Attribution International License (CC BY). http://creativecommons.org/licenses/by/4.0/

(c) (i) Open Access

\begin{abstract}
To maintain healthy and sanitary indoor air quality, development of effective decontamination measures for the indoor environment is important and hydrogen peroxide is often used as decontamination agent in healthcare environment. In this study, we focused on the decomposition phenomena of vaporized hydrogen peroxide on wall surfaces in indoor environment and discussed a wall surface decomposition model for vaporized hydrogen peroxide using computational fluid dynamics to simulate the concentration distributions of vaporized hydrogen peroxide. A major drawback to using numerical simulations is the lack of sufficient data on boundary conditions for various types of building materials and hence. We also conducted the fundamental chamber experiment to identify the model parameters of wall surface decomposition model for targeting five types of building materials.
\end{abstract}

\section{Keywords}

Vaporized Hydrogen Peroxide, Computational Fluid Dynamics, Wall Surface Decomposition Model, Chamber Experiment

\section{Introduction}

In spaces that require a high level of cleanliness, such as cleanrooms in factories, museum, healthcare center and hospitals, there is a great demand for the development of effective decontamination method in indoor environ-

*Corresponding author.

How to cite this paper: Ito, K., Yoo, S.-J. and Horata, H. (2016) Identification of Model Parameters of Vaporized Hydrogen Peroxide Decomposition Flux on Building Materials for Computational Fluid Dynamics. Journal of Environmental Protection, 7, 212-229. http://dx.doi.org/10.4236/jep.2016.72019 
ment. Decontamination by using gas-phase decontaminant agents will be essential when three-dimensional indoor spaces are contaminated by various kinds of chemical and biological contaminants. Various methods for controlling indoor air quality have been proposed and put into practical use. For example, spraying vaporized hydrogen peroxide (hereafter VHP) into the air is known as generally used biological decontamination method, i.e. fumigation, in Japan. VHP is practically used for decontamination in hospitals, airliner cabin and factories because of its high efficiency in sterilizing microorganisms in indoor spaces, especially on the wall surfaces [1]-[3].

In predicting the concentration distribution of a chemical substance, e.g. volatile organic compounds; VOCs in an indoor environment, advection-diffusion phenomena in the room and adsorption-desorption phenomena on indoor wall surfaces have been modeled and the results have been applied to various flow fields and indoor environmental conditions [4]-[9]. In addition, modeling of concentration-determining factors such as the chemical reactions of a highly reactive chemical substance such as ozone and electrophoresis produced by the charged fine particles of an electric field has been carried out in recent years and practical prediction methods for concentration distributions have been discussed [10]-[14].

In this study, we focused on spraying VHP into a space as a decontamination method for the indoor environment. We discussed numerical simulation models for wall surface decomposition as well as procedures for determining model parameters of wall surface decomposition model. Computational fluid dynamics (CFD) was used to predict the non-uniform distributions of VHP indoors. Here, a combined approach of fundamental chamber experiments and CFD simulations was used for parameterization of the wall surface decomposition model of VHP.

With regard to predicting a VHP concentration distribution based on CFD, a few studies have applied chemical reaction models and a wall decomposition model to an indoor environment and verified prediction accuracy. For example, Chen and Chen reported application of CFD to a commercial airliner cabin [15]. In this study, a first-order decay model was incorporated into the transport equation for VHP [16]. Verce et al. reported a VHP decomposition model using CFD simulation and also determined model parameters using a cylindrical test chamber experiment [17]. They focused on relatively high VHP concentrations and used only galvanized steel as the decomposition wall surface. The aim of this study was to determine the model parameters of VHP wall surface decomposition model for various building materials, focusing on relatively low VHP concentrations [18] [19].

\section{Vaporized Hydrogen Peroxide}

VHP is an unstable chemical substance with high oxidizability and a bactericidal effect [1]-[3] [20]. Furthermore, at high concentrations, VHP can decompose spore-forming bacteria with highly durable cell structures. One of the advantages of using VHP is its ability to sterilize in a short timeframe. A hydrogen peroxide $\left(\mathrm{H}_{2} \mathrm{O}_{2}\right)$ aqueous solution at a concentration of $2.5 \%-3.5 \% \mathrm{w} / \mathrm{v}$ is commercially available as Oxydol under the Japanese Pharmacopoeia as a topical disinfectant for medical use and is used as a sterilization method in practice. Because VHP eventually decomposes into water $\left(\mathrm{H}_{2} \mathrm{O}\right)$ and oxygen $\left(\mathrm{O}_{2}\right)$, no hazardous substances remain and VHP can be handled easily. On the other hand, the wall surface deposited/adsorbed VHP contributes to decontamination on the wall surfaces in indoor environment. Therefore, development of computational methods to accurately predict the amount of surface VHP decomposition and subsequent VHP concentration distributions in indoor environment is an important goal of this study.

In indoor decontamination with VHP, because the VHP concentration in the air is on the order of parts per million (ppm) and the residence time is short (less than a few hours), it is difficult to ensure adequate reaction probability (collision) between $\mathrm{H}_{2} \mathrm{O}_{2}$ molecules and the targeted contaminant in the air with sufficient reaction time. Therefore, it is difficult to improve the decontamination efficiency in the air; thus, the bactericidal effect is targeted at wall-attached bacteria on a solid wall surface.

The reaction mechanism between VHP absorbed or deposited on a wall surface and the wall-attached bacteria remains unclear. In particular, it is uncertain whether $\mathrm{H}_{2} \mathrm{O}_{2}$ exerts a sterilization effect after being emitted into the room air by adsorbing onto the wall and reacting with the wall-attached bacteria (the so-called dry process) or whether the $\mathrm{H}_{2} \mathrm{O}_{2}$ in an aerosol layer or solution layer reacts with the wall-attached bacteria after a phase change from gas to a liquid/aerosol at the wall surface (the so-called wet process). However, in terms of the contact probability with wall-attached bacteria, if the $\mathrm{H}_{2} \mathrm{O}_{2}$ condenses so that it surrounds the wall-attached bacteria, decontamination effect will be improved. It is important to maximize the amount of VHP deposited/ 
adsorbed onto the surface (termed "decomposition" in this study) while minimizing reactions between the wall covering material and VHP. Although VHP is typically generated by heating with a vaporizer/evaporating device, it is uncertain whether all of the $\mathrm{H}_{2} \mathrm{O}_{2}$ emitted remains gaseous or becomes an aerosol by condensation/clustering when it is emitted into the room air.

Therefore, to develop a series of mathematical models describing the sterilization effect of VHP, it is necessary to specifically clarify the status of VHP in the air, the rate of decrease of the VHP concentration in the air, decomposition phenomena, and reaction phenomena on the solid surface. In this study, we discussed the fundamental equations required to predict the amount of surface decomposition of VHP based on the assumption that existing chemical reaction models can be applied to a VHP transport model. Here, vaporized hydrogen peroxide was assumed to be gas phase and to be subjected to the fundamental kinetic theory of molecules.

\section{Reaction Modeling of Vaporized Hydrogen Peroxide}

A few reaction models and analytical cases have utilized CFD, as noted above. For example, Verce et al. analyzed an experimental apparatus for a duct system, simulating decomposition on the wall while ignoring selfattenuation of VHP in the air [17]. Their analysis incorporated a decomposition model of the Langmuir type (as shown in Equation (9)), which used the concentration dependence of the first layer of cells adjacent to the wall surfaces as a sink term.

It is challenging to simulate decomposition on the wall while including the phase change, because of the heavy load on the computer and the need to identify model constants. Therefore, in this study, we assumed that vaporized hydrogen peroxide was in the gas phase (i.e., VHP) and simplified representation of the concentration by converting the values to a concentration in the gas phase.

\subsection{Reaction Model Using a Reaction Rate Constant}

Assuming the concentration of VHP at a point in space to be $C$ and the concentration of a pollutant reacting with VHP in the air to be $C_{i}$, the transport of VHP is expressed by Equation (1), a Reynolds-averaged Navier-Stokes (RANS) equation system with an applied ensemble mean:

$$
\frac{\partial \bar{C}}{\partial t}+\frac{\partial \overline{U_{j} \bar{C}}}{\partial x_{j}}=\frac{\partial}{\partial x_{j}}\left(\left(D+\frac{v_{t}}{\sigma_{t}}\right) \frac{\partial \bar{C}}{\partial x_{j}}\right)+S_{u}+S_{b}
$$

where an overbar denotes the ensemble mean value, $D\left(\mathrm{~m}^{2} / \mathrm{s}\right)$ is the molecular diffusion coefficient of VHP, $U_{j}$ $(\mathrm{m} / \mathrm{s})$ is the ensemble-mean velocity, $v_{t}\left(\mathrm{~m}^{2} / \mathrm{s}\right)$ is the turbulent eddy viscosity, and $\sigma_{t}$ is the turbulent Schmidt number. The source terms for the chemical reaction can be simply modeled by the following first-order and second-order reactions in the air [10] [13]:

$$
\begin{aligned}
& S_{u}=-k_{u} \cdot \bar{C} \\
& S_{b}=-k_{b} \cdot \bar{C} \cdot \overline{C_{i}}
\end{aligned}
$$

where $k_{u}$ is the first-order reaction rate constant for self-attenuation and $k_{b}$ is the second-order reaction rate constant for the reaction between VHP and microorganisms in the air. $S_{u}$ represents the loss of $C$ through the first-order reaction (self-attenuation) of VHP in the air, while $S_{b}$ represents the loss of $C$ through the intermolecular reaction between VHP and the pollution in the air. Equation (1) was solved by applying the wall boundary condition. Thus, we used source term modeling for the wall surface decomposition flux model and hence, source term $S$ represents the decomposition reaction rather than first-order/second-order chemical reactions in the air phase.

\subsection{Modeling Wall Surface Decomposition Flux}

Concerning the interaction between gas-phase VHP adjacent to wall surface and wall surface itself, we use the term decomposition in accordance with Verce et al. [17].

To estimate decontamination at the wall by VHP, it is necessary to predict the amount of decomposition relative to the time-integrated value. In previous studies, deposition phenomenon of gas-phase chemical compound was modeled using a deposition flux equation based on molecular theory [21] [22]. Assuming the decrease in the 
rate of VHP colliding with the wall surface to be $\gamma$, the average thermal velocity $(\mathrm{m} / \mathrm{s})$ of VHP to be $\langle v>$, and the concentration of VHP in the immediate vicinity of the wall ( $2 \lambda / 3 \mathrm{~m}$ from the wall) to be $\left.\bar{C}\right|_{y=2 \lambda / 3}$, the decomposition flux $J_{d}$ of VHP in the immediate vicinity of the wall can be expressed as [21]:

$$
J_{d}=-\left.\gamma \cdot \frac{\langle v\rangle}{4} \cdot \bar{C}\right|_{y=2 \lambda / 3}
$$

In the immediate vicinity of the wall, the decomposition property for VHP can be expressed as follows:

$$
\gamma=\frac{r_{1}}{r_{2}}
$$

where $r_{1}$ is the amount of VHP that is removed from the air after it collides with the wall surface and $r_{2}$ is the total amount of VHP that collides with the wall surface. In addition to Equation (4), if the flux from a discretely defined point to distance $2 \lambda / 3$ is determined by molecular diffusion, the decomposition flux $J$ of VHP from this point to the wall ( $\Delta y_{1}$ away from the point) is expressed as follows [13] [22]:

$$
\begin{aligned}
& J=-\left.\frac{\gamma \cdot \frac{\langle v\rangle}{4}}{1+\gamma \cdot \frac{\langle v\rangle}{4} \cdot \frac{\Delta y_{1}}{D}} \cdot \bar{C}\right|_{y=\Delta y_{1}} \\
& J=-\left.v_{d} \cdot \bar{C}\right|_{y=\Delta y_{1}}
\end{aligned}
$$

where $\left.\bar{C}\right|_{y=\Delta y_{1}}$ is the VHP concentration at the discretely defined point, $v_{d}$ is the deposition velocity $(\mathrm{m} / \mathrm{s}) . \Delta y_{1}$ in Equation (6) is the distance of the defined point from the wall when the wall unit $y^{+}$(dimensionless normal distance from the wall boundary surface) is $<1$ [13]. The flux modeling by using deposition velocity concept is generally adopted and simple definition is shown in Equation (7). $\Delta y_{1}$ in Equation (7) is the distance of the defined point from the wall when the wall unit $y^{+}$is $30-100$ (generally log-law region or outer of boundary layer). The above models give a linear decomposition flux as a boundary condition. Equation (6) represents a viscous sublayer as the boundary layer and Equation (7) is a simple model for use outside of the concentration boundary layer of the wall surface as a reference concentration. The deposition velocity concept is similar and analogous to mass transfer coefficient.

On the other hand, in the approach of Verce et al. [17]. shown above, decomposition was modeled by only using the sink term $S$ for the first layer of cells adjacent to the wall. For example, the following linear and Sigmoid type models can be used:

$$
\begin{aligned}
& S=-\left.K \cdot \bar{C}\right|_{y=\Delta y_{1}} \\
& S=-\left.\frac{K_{1} \bar{C}}{K_{2}+\bar{C}}\right|_{y=\Delta y_{1}}
\end{aligned}
$$

In this study, we adopted two wall surface decomposition models, Equation (6) and Equation (8), and the model parameters of these wall surface decomposition models are identified by fundamental experiments and corresponding CFD simulations. The wall surface decomposition model represented by Equation (6) is flux type model and is applied as wall surface boundary condition of CFD simulation. On the other hand, the decomposition model represented by Equation (8) is source term model and is applied the first cells attached wall surface boundary. The prediction accuracy of these two models is equivalent (if the first grid point is satisfied with $y^{+}<$ 1). Generally, the boundary condition setting of commercial CFD codes will have restrictions and hence these two types of wall surface decomposition models will be able to be used properly according to the situation of the commercial CFD code.

\section{Basic Experiments for Identifying Decomposition Model Parameters}

Fundamental chamber experiments with a rectangular duct apparatus were conducted to identify the model parameters for the wall surface decomposition models of VHP. 


\subsection{Overview of the Rectangular Duct Apparatus and the Concentration Measurement System}

Figure 1 shows the layout and appearance of the rectangular duct-type chamber constructed of stainless steel. The inner surface of the stainless steel was well polished and mirror finished. The chamber had two mechanical fans to regulate the air pressure and flow profiles. The main test section consisted of two 4.0-m-long rectangular portions and connected with a half-circular cross-section ( $R$-shape bent) with a radius of $0.3 \mathrm{~m}$. The mean wind speed in the test section could be adjusted from 0.1 to $3.0 \mathrm{~m} / \mathrm{s}$ using an inverter to control the fans.

To measure the decrease in VHP concentration in the gas phase through wall decomposition, stainless steel sampling tubes were installed in the test section at intervals of $0.5 \mathrm{~m}$. The tested building materials were placed on the lower part of the test section (floor face). The dimensions of the test section were set $0.02 \mathrm{~m}$ high $\times 0.1 \mathrm{~m}$ wide to increase the contact probability between the building material and the VHP (see Figure 1).

Clean air supplied to the rectangular duct apparatus was generated by eliminating particulate matter with an ultra-low penetration air filter (ULPA) after removing chemical pollutants from dehumidified fresh air using a charcoal filter and chemical filter. We confirmed that the volatile organic compounds (VOCs) in the supplied air had reasonably low concentrations using gas chromatography/flame ionization detector (GC/FID) analysis after sampling with Tenax GR. Moreover, based on wide-range particle spectrometer (WPS) measurements (MSP model 100XP), the aerosol concentration in the supplied air was confirmed to be below the detection limit. A WPS can measure the particle size distribution from $10 \mathrm{~nm}$ to $10 \mu \mathrm{m}$ by combining a condensation particle counter (CPC), differential mobility analyzer (DMA), and laser particle spectrometer (LPS).

A $30 \% \mathrm{H}_{2} \mathrm{O}_{2}$ solution from WAKO Co., Ltd (Japan) was used to generate VHP at a constant concentration using a bubbling method in which dry air passed through $300 \mathrm{~mL}$ of the $\mathrm{H}_{2} \mathrm{O}_{2}$ solution in a flask. The quantity of VHP generated was determined by measuring weight changes in the $\mathrm{H}_{2} \mathrm{O}_{2}$ solution with an electronic balance,

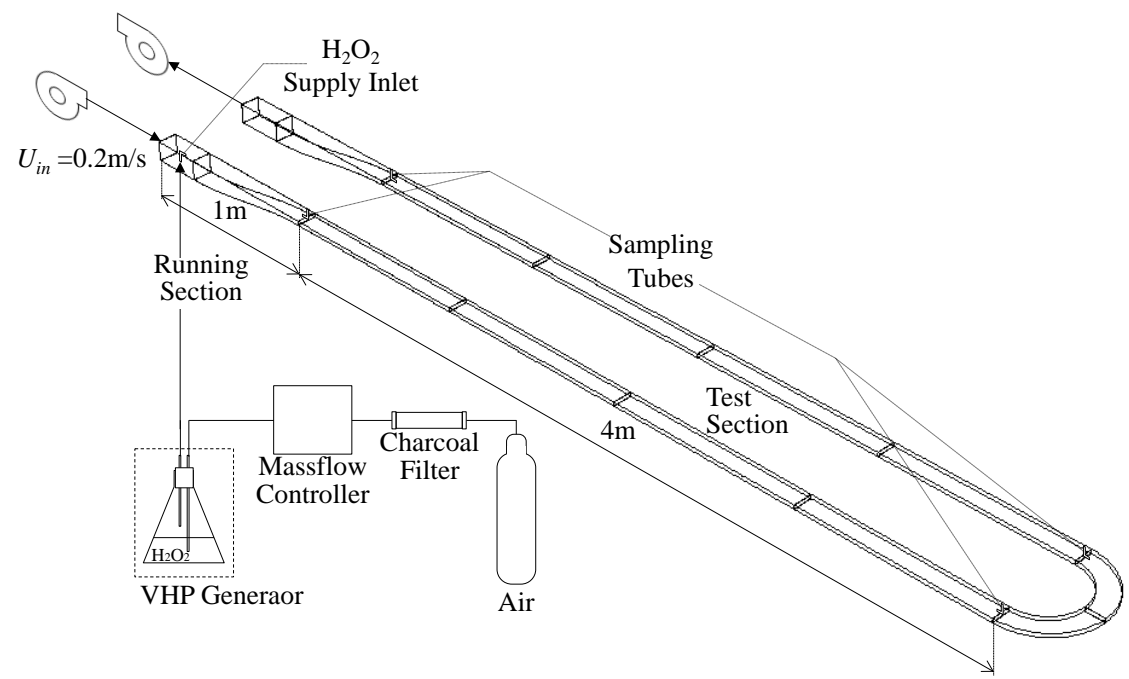

(1) Outline of the duct-type test chamber

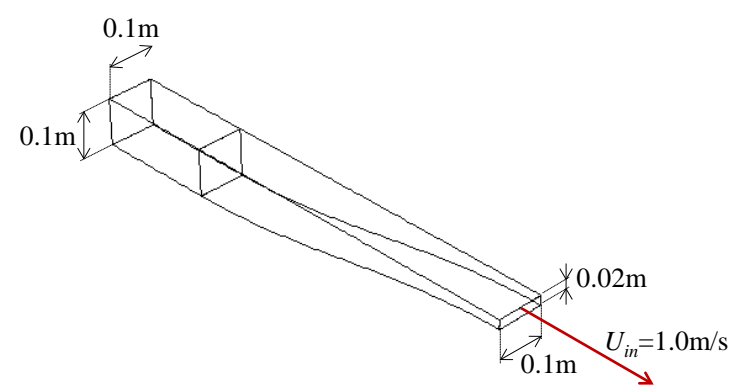

(2) Running section

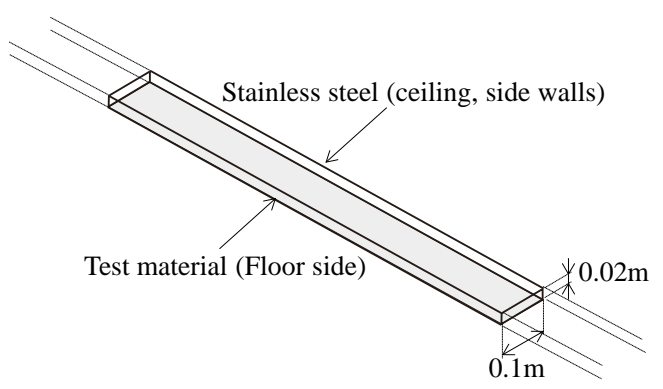

(3) A part of test section

Figure 1. Experimental setup. 
while simultaneously measuring the concentration in the supplied air upstream of the rectangular duct apparatus. VHP concentrations in the air were continuously measured using an electrochemical sensor (Drager Polytron 7000 ) with a resolution of $0.1 \mathrm{ppm}$, calibrated at 0 and $300 \mathrm{ppm}$. Results are presented as time-averaged values over $30 \mathrm{~min}$.

\subsection{Experimental Conditions}

A constant concentration of VHP was supplied upstream of the rectangular duct chamber and the reduction in concentration of VHP passing through the duct (particularly over the surface of the building materials) was measured. The mean wind speed in the rectangular duct chamber (test section) was controlled at $1.0 \mathrm{~m} / \mathrm{s} \pm 10 \%$. The flow rate in the duct was continuously confirmed by measuring the pressure difference between the front and rear orifices using a digital pressure gage. The wind speed in the test section of the duct was calculated by dividing the flow rate by the cross-sectional area of the test section.

The VHP concentration in the air supplied to the duct was gradually increased from 0.5 to $10 \mathrm{ppm}$ to evaluate the concentration dependence of the wall surface decomposition. This concentration range is relatively low compared to typical VHP concentrations used in indoor sterilization ( $\sim 100 \mathrm{ppm})$. Previous reported paper focused high VHP concentration condition ( $\sim 800 \mathrm{ppm})$ [17], and there is no study in the low VHP concentration ( $\sim 10$ ppm). In general, non-uniform VHP concentration distributions will be formed in indoor environment and there will be a possibility to form a low concentration at local domain. In this point of view, VHP decomposition data in the low concentration level will contribute to the practical application of VHP sterilization in indoors.

All of the experiments were conducted at a constant room and air temperature of $22.2^{\circ} \mathrm{C} \pm 1.0^{\circ} \mathrm{C}$.

The entire rectangular duct chamber was constructed of stainless steel. Therefore, we first estimated the VHP decomposition rate on the stainless steel surfaces in the test section, including all of the faces on the upper (ceiling), lower (floor), left, and right side walls, to understand the background amount of decomposition on the stainless steel. We then placed the tested building materials (test specimen) on only the lower wall (floor) of the test section and measured the decrease in the VHP concentration when VHP was supplied at a constant concentration. The experimental cases, including the list of tested building materials, are summarized in Table 1. Five materials were tested: the stainless steel (SUS304 Japan Industrial Standard), flooring material (Vinylester resin) for a clean room, heat-resistant glass (Pyrex), plywood (which is widely used as building material in Japan), and a wall material (Calcium silicate board with ultraviolet curable resin) for a clean room. Photos of the tested building materials are shown in Figure 2.

Table 1. Cases analyzed.

\begin{tabular}{|c|c|c|c|}
\hline Case & Test material & Test conditions in the test section & Initial (inlet) VHP concentration $C_{i n}$ \\
\hline Case 0 & Stainless steel (SUS304) & & $0.82 \pm 0.10-12.87 \pm 0.12 \mathrm{ppm}$ \\
\hline Case 1 & Floor material (resin) & $U_{\text {in }}=1.0 \mathrm{~m} / \mathrm{s} \pm 10 \%$ & $3.63 \pm 0.05-12.53 \pm 0.16 \mathrm{ppm}$ \\
\hline Case 2 & Pyrex glass & $\begin{array}{c}T_{i n}=22.2^{\circ} \mathrm{C} \pm 10 \% \\
R H_{\text {in }} \ll 5 \%\end{array}$ & $3.68 \pm 0.17-12.47 \pm 0.39 \mathrm{ppm}$ \\
\hline Case 3 & Plywood & & $3.45 \pm 0.10-12.10 \pm 0.11 \mathrm{ppm}$ \\
\hline Case 4 & Wall material (resin) & & $6.07 \pm 0.05-10.73 \pm 0.10 \mathrm{ppm}$ \\
\hline
\end{tabular}

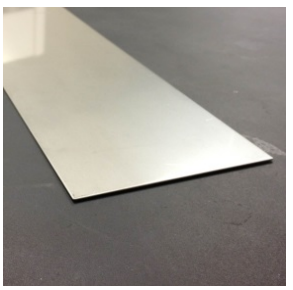

Stainless steel

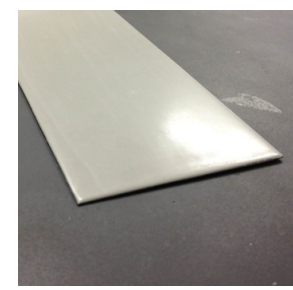

Floor material (resin)

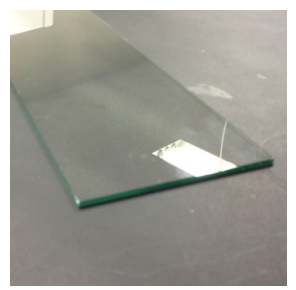

Pyrex glass

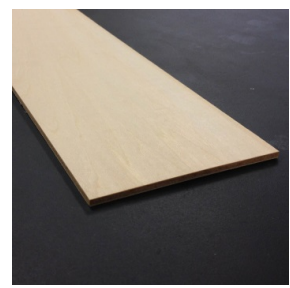

Plywood

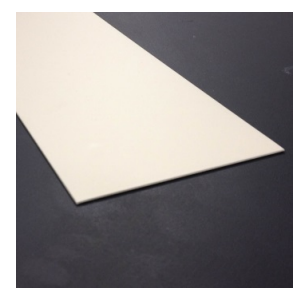

Wall material (resin)

Figure 2. Photos of tested building materials. 


\section{Numerical Analysis for Identification of Decomposition Model Parameters}

We conducted a CFD analysis that precisely reproduced the geometry and boundary conditions of the rectangular duct chamber and then analyzed concentration decreases in the duct under these conditions using wall decomposition models for VHP. We applied Equations (6) and/or (8) to the CFD analysis as the wall decomposition model for VHP and parametrically varied each model parameter. In this way, we determined the relationship between the decrease in concentration $\left(C_{\text {out }} / C_{i n}\right)$ and the model parameters for each decomposition flux model.

\subsection{Overview of the Computational Fluid Dynamics Analysis}

We precisely reproduced the inner geometry of the rectangular duct chamber from the running section (constricted flow section and upstream of the test section) to the expanded section downstream and overlaid a CFD analysis mesh. In the test section, a fine mesh of approximately $0.1 \mathrm{~mm}$ or less was used as the first layer of mesh on the building material surface to resolve the flow profile in the viscous sub-layer. The number of meshes was set to approximately 3,000,000 for the rectangular duct model. For this analysis case, the wall unit $y^{+}$was $\leq 1$ in all areas, where $y^{+}=u^{*} y_{1} / v ; y_{1}$ is the distance normal to the wall surface, $v$ is the kinematic viscosity, and $u^{*}=\sqrt{\tau_{w} / \rho}$ is the friction velocity ( $\rho$ is the air density and $\tau_{w}$ is the wall shear stress). In this CFD simulation, grid independence check was carefully executed and minimum mesh size in the vicinity of wall surface, skewness and size ratio of adjoining mesh were elaborately designed.

The entire flow field in the rectangular duct chamber was analyzed using a low-Reynolds-number $k$ - $\varepsilon$ model (Abe-Kondoh-Nagano model) [23]. Generally, the low-Reynolds-number $k-\varepsilon$ model was designed to account for damping and echo effects in the near wall region; it is also applied to quasi-laminarized flow fields existing within stable stratifications. The model implements damping and model functions, and performs low-Reynolds number corrections for the production and dissipation terms of the eddy viscosity $\mu_{t}$ and $\varepsilon$ equations. The lowReynolds number $k-\varepsilon$ model can reproduce turbulence phenomena found around walls that result from trying to solve adequately refined mesh partitions under no-slip conditions in the region around the wall. This low Reynolds number type turbulence model (Abe-Kondoh-Nagano model) has been adopted for the various types of flow field analysis (from laminar to turbulence) and confirmed the good prediction accuracy to flow field analysis intended for enclosed space [24].

The SIMPLE algorithm was used as the computation algorithm. A second-order upwind difference scheme was used for the convection terms and a center difference scheme was used for the other terms. The experiments were conducted under isothermal conditions and thus, the CFD analysis applied the same conditions.

Concerning the VHP concentration distribution analysis, hydrogen peroxide in air was assumed to be gas phase in accordance with the previous reported papers [15] [17]. The transport equation for the VHP concentration using the ensemble average was calculated after the steady flow field was analyzed. Here, two models were used for the wall decomposition flux model for VHP. Equation (6), which is the wall decomposition model, was applied as the wall surface boundary condition. In this CFD simulation, low-Reynolds-number $k-\varepsilon$ model was applied as turbulence model and flow profile inside viscous sub-layer was precisely analyzed. Wall surface decomposition model intended inside viscous sub-layer, i.e. Equation (6) and-or Equation (8), was used in this study. Equation (8) was the source term model and hence, was applied only to the first layer of cells adjacent to the wall; the other cells were set to zero. The analyses were conducted under these two conditions. The turbulent Schmidt number $\sigma_{t}$ in the transport equation for VHP (Equation (1)) was set to 1.0.

The supply inlet of the rectangular duct apparatus had a $0.1 \mathrm{~m} \times 0.1 \mathrm{~m}$ cross-section, at which the boundary condition of $U_{\text {in }}=0.2 \mathrm{~m} / \mathrm{s}$ was applied. Further downstream, the cross-section was constricted to $0.02 \mathrm{~m} \times 0.1 \mathrm{~m}$, the size of the test section, via a bell-mouth-type squeezing part. The mean wind speed in the test section was $1.0 \mathrm{~m} / \mathrm{s}$ in the test section. Table 2 lists the numerical and boundary conditions.

Figure 3 shows the results of the flow field analysis. The comparatively uniform flow profile was formed in the former part of test section (upstream side) and obvious non-uniform flow pattern was generated in a halfcircular cross-section ( $R$-shape bent) and the latter part of test section (downstream side) in the rectangular duct chamber.

\subsection{Chart for Identification of Model Parameters}

Prior to the experiments, we conducted a CFD simulation and evaluated the relationship between the decompo- 
Table 2. Numerical and boundary conditions.

\begin{tabular}{|c|c|}
\hline Turbulence model & Low Re type $k-\varepsilon$ model (Abe-Kondoh-Nagano model [23], three-dimensional) \\
\hline Mesh & 3,007,680 mesh (wall unit $y^{+}<1$ ) \\
\hline Scheme & Convection term: second-order upwind \\
\hline Inflow boundary & $\begin{array}{l}U_{\text {in }}=0.2 \mathrm{~m} / \mathrm{s} \text { (inlet air velocity in the running section, which corresponds to an average of } 1.0 \mathrm{~m} / \mathrm{s} \text { air } \\
\text { velocity in the test section) } \\
k_{\text {in }}=3 / 2\left(0.1 U_{\text {in }}\right)^{2}, \quad \varepsilon_{\text {in }}=C_{\mu}^{3 / 4} k_{\text {in }}^{3 / 2} / l_{\text {in }}, C_{\mu}=0.09, l_{\text {in }}=0.02 \mathrm{~m}\end{array}$ \\
\hline Outflow boundary & $U_{\text {out }}=$ free slip, $k_{\text {out }}=$ free slip, $\varepsilon_{\text {out }}=$ free slip \\
\hline Wall treatment & $\begin{array}{l}\text { Velocity = no-slip } \\
\text { VHP Equation (6) or (8) }\end{array}$ \\
\hline VHP & Passive scalar (turbulent Schmidt Number $\sigma_{t}=1.0$ ) \\
\hline \multicolumn{2}{|l|}{ Exhaust Outlet } \\
\hline \multicolumn{2}{|l|}{ Supply Inlet } \\
\hline $\begin{array}{rrr}0.4 & 0.81 .2\end{array}$ & $1.6=$ \\
\hline \multicolumn{2}{|l|}{ Exhaust Outlet } \\
\hline Supply Inlet & \\
\hline
\end{tabular}

Figure 3. Velocity distribution in the duct-type test chamber $(\mathrm{m} / \mathrm{s})$. (Upper figure shows the velocity distribution in horizontal plane at the center of test section/Lower figure shows the velocity distribution in vertical plane at the center of test section).

sition properties of VHP and the concentration decrease between the supply inlet $\left(C_{\text {in }}\right)$ and the exhaust outlet $\left(C_{\text {out }}\right)$ of the test section by analyzing the VHP concentration change in the test section of the rectangular duct apparatus. By using these CFD simulation results, we prepared an identification chart to represent the relationship between the decrease in concentration $\left(C_{\text {out }} / C_{i n}\right)$ and each model parameter (reaction probability $\gamma$ in Equations (6) or first-order rate constant $K$ in Equations (8)) in order to identify the model parameters in Equations (6) and (8). Three types of identification chart are shown in Figures 4-6. Details of the analytical procedure and these identification charts are described in following two cases.

\section{1) Estimating the background amount of decomposition on stainless steel}

The entire rectangular duct chamber was constructed of stainless steel (SUS304). Therefore, Figure 4 shows the analysis results for the supply inlet and exhaust outlet of the test section when $\gamma$ was gradually varied after applying Equation (6) to the upper, lower, left, and right faces of the rectangular duct chamber. Here, $\gamma$ expresses reaction probability of gas-phase VHP and building material surface (originally defined in Equation (5)), and this Figure 4 denotes the identification chart for reaction probability $\gamma$ in case of stainless steel as background for decomposition of VHP. We assumed that $\gamma$ was concentration-independent in the decomposition flux model (Equation (6)). Therefore, the concentration field analysis was non-dimensionalized to the concentration at the supply inlet of the test section. $\gamma$ for stainless steel was identified by the decrease in the VHP concentration in the subsequent experiment, designed to be overlapped onto this chart. In this experiment, reaction terms other than the wall decomposition effect were neglected, because the nominal time constant $\tau_{n}$ (representative ventilation time $\left[\mathrm{s}\right.$ ] calculated from the airflow rate $\left(\mathrm{m}^{3} / \mathrm{s}\right)$ and the chamber volume $\left(\mathrm{m}^{3}\right)$ and represents average air change time in piston flow) was approximately $8 \mathrm{~s}$, which was very short.

2) Estimating the decomposition property $\gamma$ of building materials placed on the floor

Figure 5 shows the concentration difference between the supply inlet and the exhaust outlet of the test section simulating placement of the building materials on the floor of the test section. This Figure 5 denotes the identification chart for reaction probability $\gamma$ in case of tested building materials. The sigmoid type relation between concentration ratio $\left(C_{\text {out }} / C_{i n}\right)$ and reaction probability $\gamma$ was observed. In this case, a constant value of $\gamma$ for 


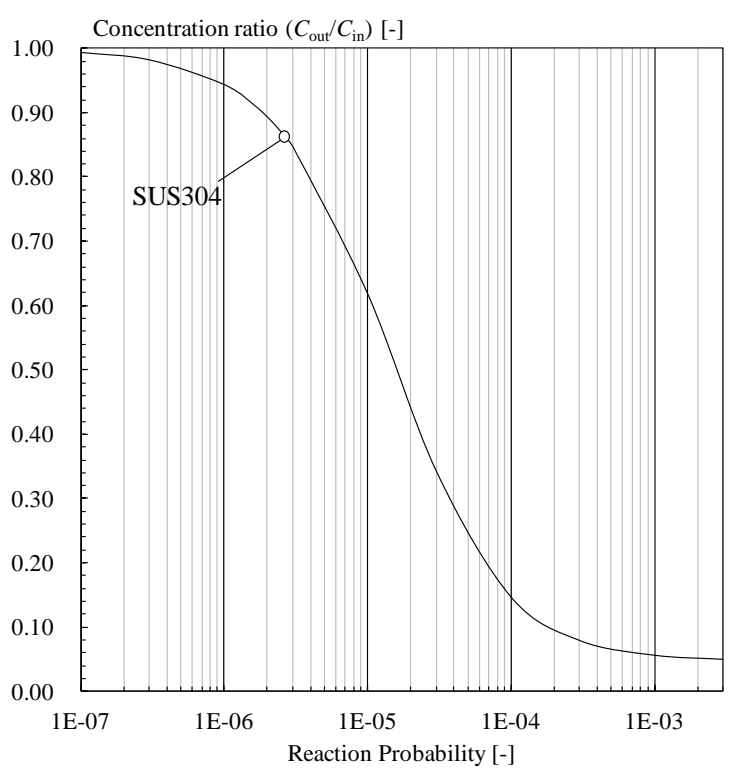

Figure 4. Identification chart for reaction probability $\gamma$ (stainless steel as background for decomposition of VHP).

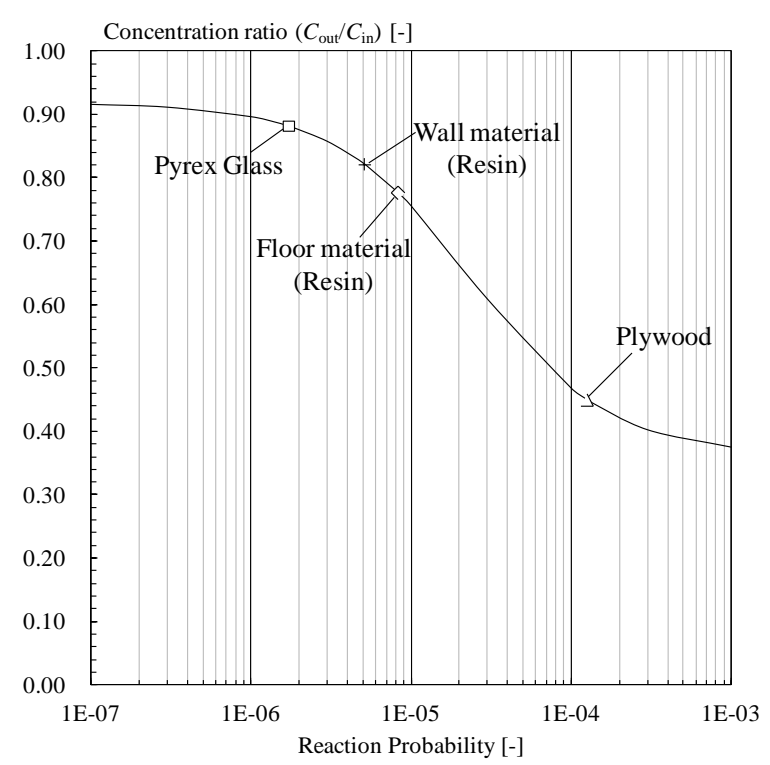

Figure 5. Identification chart for reaction probability $\gamma$ (tested building materials).

stainless steel was assigned to the upper, left, and right faces of the inner duct chamber, excluding the lower face. The values of $\gamma$ for the tested building materials were determined by the decrease in VHP concentrations in the subsequent experiment, overlapped onto this chart.

After estimating the decomposition property $\gamma$ (reaction probability), the decomposition property $K$ (first order rate constant) of Equation (8) was also estimated. $K$ is the model coefficient that determines the sink term $S_{d}$ in the first layer of cells adjacent to the wall. The procedure for chart preparation for $K$ was the same as for $\gamma$. Figure 6 shows the chart for estimating $K$ in the source (sink) term of the model (Equation (8)).

\subsection{Experimental Results and Estimation of $\gamma$}

Figure 7 shows the measured inlet concentrations $C_{i n}$ and outlet concentrations $C_{\text {out }}$ when the building materials 


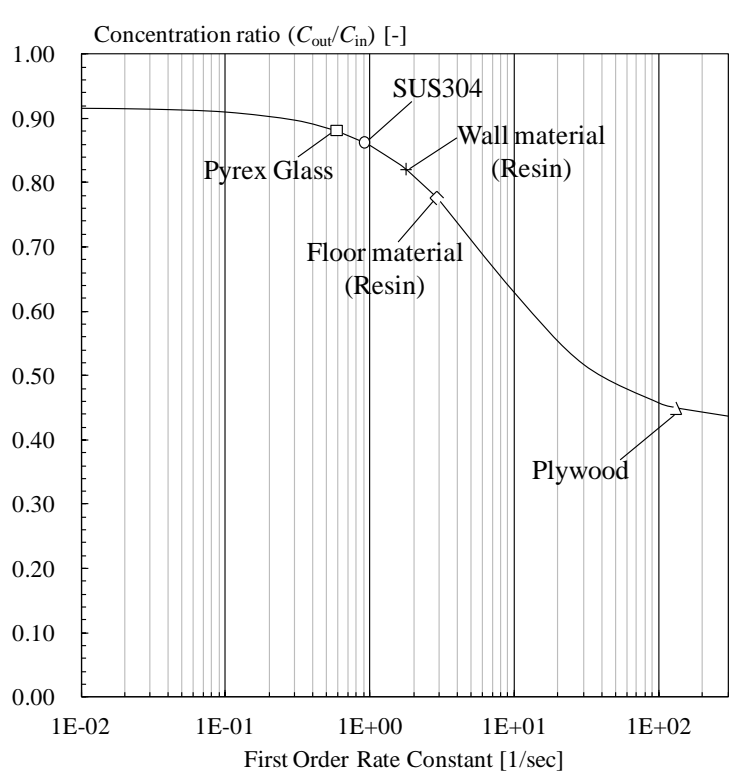

Figure 6. Identification chart for model parameter $K$ for testing materials.

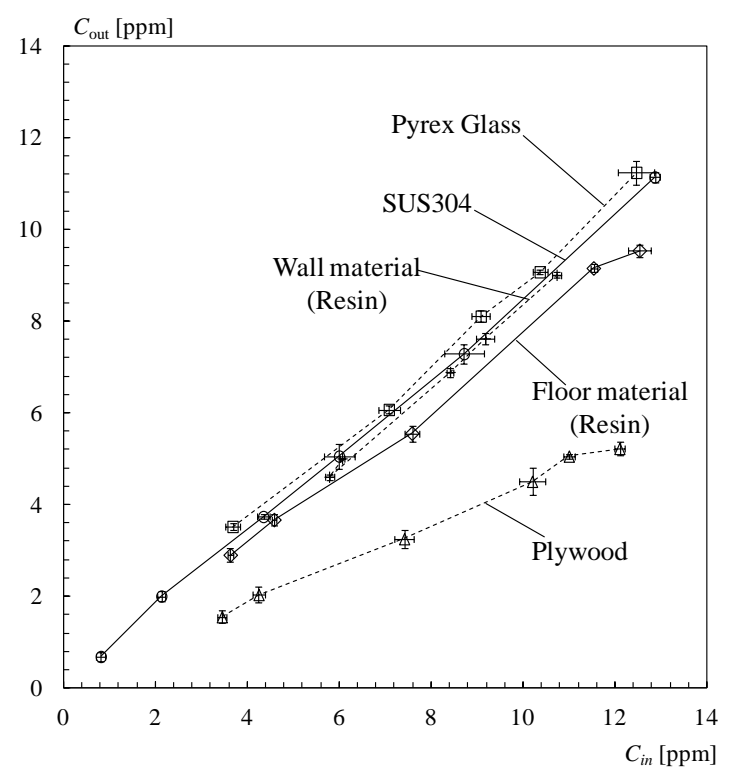

Figure 7. Experimental results for the VHP concentration at the exhaust outlet $C_{\text {out }}$ as function of the concentration at the supply inlet $C_{i n}$.

were placed on the floor of the test section and VHP was supplied at a constant concentration upstream of the rectangular duct apparatus. In all building materials, the relation of almost linear between $C_{\text {in }}$ and $C_{\text {out }}$ was observed in this VHP concentration range. Table 3 lists the model parameters for the decomposition flux model determined using the concentration ratio $\left(C_{\text {out }} / C_{\text {in }}\right)$ and identification chart shown in Figure 5.

The case in which building materials were not placed in the test section represents that in which the upper, lower, left, and right faces of the test section were stainless steel (SUS304); the concentration ratio $\left(C_{\text {out }} / C_{\text {in }}\right)$ in this case was approximately 0.78 when VHP was supplied at $0.82 \pm 0.01$ to $12.87 \pm 0.12 \mathrm{ppm}$. Thus, concentration dependence was not observed. By overlapping this concentration ratio onto the chart in Figure 4, we could determine that $\gamma$ for stainless steel (SUS304) was approximately $2.64 \times 10^{-6}$. The identification chart for the 
Table 3. Estimation of the reaction probability $\gamma$.

\begin{tabular}{ccc}
\hline Test material & Concentration ratio $\left(C_{\text {out }} / C_{\text {in }}\right)$ & Reaction probability $\gamma$ \\
\hline Stainless steel (SUS304) & 0.86 & $2.64 \times 10^{-6}$ \\
Floor material (resin) & 0.78 & $8.25 \times 10^{-6}$ \\
Pyrex glass & 0.88 & $1.72 \times 10^{-6}$ \\
Plywood & 0.45 & $1.26 \times 10^{-4}$ \\
Wall material (resin) & 0.82 & $5.13 \times 10^{-6}$ \\
\hline
\end{tabular}

model parameter $\gamma$ in Figure 5 was constructed using a constant value for $\gamma$ of $2.64 \times 10^{-6}$ for the stainless steel (SUS304) surfaces; the analysis was conducted only at the floor where the value of $\gamma$ was varied sequentially.

The case in which a building material was placed on the floor of the test section represents that in which the floor of the test section was made of the building material and the upper, left, and right faces of the test section were stainless steel (SUS304). For the flooring material (resin), the concentration ratio $\left(C_{\text {out }} / C_{\text {in }}\right)$ was approximately 0.78 with VHP supplied at $3.63 \pm 0.05$ to $12.53 \pm 0.16 \mathrm{ppm}$. For Pyrex glass, the concentration ratio $\left(C_{\text {out }} / C_{\text {in }}\right)$ was approximately 0.88 with VHP supplied at $3.68 \pm 0.17$ to $12.47 \pm 0.39 \mathrm{ppm}$. For plywood, the concentration ratio $\left(C_{\text {out }} / C_{\text {in }}\right)$ was approximately 0.45 with VHP supplied at $3.45 \pm 0.10$ to $12.1 \pm 0.11 \mathrm{ppm}$. Finally, for the wall material (resin), the concentration ratio $\left(C_{\text {out }} / C_{\text {in }}\right)$ was approximately 0.82 with VHP supplied at 6.07 \pm 0.05 to $10.73 \pm 0.10 \mathrm{ppm}$. By overlaying these concentration ratios onto the chart in Figure 5, we estimated that the value of $\gamma$ for the floor material (resin) was approximately $8.25 \times 10^{-6}, \gamma$ for Pyrex glass was approximately $1.72 \times 10^{-6}, \gamma$ for plywood was approximately $1.26 \times 10^{-4}$, and $\gamma$ for the wall material (resin) was approximately $5.13 \times 10^{-6}$.

\subsection{Estimation of the Model Parameter $K$ of the Linear Decomposition Model}

The model parameter $K$ of the linear sink term model $S_{d}$ in Equation (8) can be determined using the measured inlet concentration $C_{\text {in }}$ and outlet concentration $C_{\text {out }}$. Table 4 lists the results for $K$ based on the experimental data assuming perfect mixing in the duct chamber, and that based on combined CFD analysis. By using CFD simulation, development of VHP boundary layer on the building material surface could precisely reproduced and impact of non-uniformity of decomposition of VHP on the building material surface was able to incorporate into $K$ parameterization. The $K$ estimated from the experimental data was calculated as $\left(\left(C_{\text {out }}-C_{i n}\right) / C_{i n}\right) / \tau_{n}$. Here, $\tau_{n}$ is the nominal time constant calculated using the flow rate $Q_{i n}$ and test cross-sectional volume $V$. Table 4 also lists estimates of the model parameter $K$ based on fitting the experimental results to the chart in Figure 6. These results are equivalent to estimates of the model parameter $K$ determined by CFD using a non-uniform concentration field and hence, are termed " $K$ estimated by CFD."

The values for the model parameter $K$ estimated using only the experimental results ( $K$ estimated by experiment) were approximately two orders of magnitude smaller than those estimated by CFD ( $K$ estimated by CFD). A relatively simple uniform flow formed in the rectangular duct apparatus used in this experiment, along with a concentration boundary layer for VHP and an area effect at the building material surface or the reaction plane. However, with a non-uniform flow field, a non-uniform concentration field formed in the chamber, along with a reference concentration change from upstream to downstream. This suggests that it is important to estimate the model parameters incorporating these non-uniform features.

In case of the experiments and results reported by Verce et al. [17], sigmoid type model (i.e. Langmuir model in Equation (9)) was adopted to reproduce the decomposition effect of VHP on the wall surfaces. In Verce et al. [17], for galvanized steel and a relatively high VHP concentration (approximately $800 \mathrm{ppm}$ ), $K_{1}$ was estimated to be $4.0 \mathrm{mg} / \mathrm{L} \cdot \mathrm{s}$ and $K_{2}$ was $1.9 \mathrm{mg} / \mathrm{L}$ for an ambient temperature of $21.8^{\circ} \mathrm{C}$, whereas $K_{1}$ was $9.0 \mathrm{mg} / \mathrm{L} \cdot \mathrm{s}$ and $K_{2}$ was $1.3 \mathrm{mg} / \mathrm{L}$ when the ambient temperature was $30.2^{\circ} \mathrm{C}$. In our experiments, we assumed relatively low VHP concentration and obvious concentration dependence against the conversion rate of VHP on the wall surface was not observed. This was the reason to adopt the linear type model as shown in Equation (8) in this study. Though the direct comparison of estimated parameters $\left(K_{1}\right.$ and $\left.K_{2}\right)$ by Verce et al. [17] and $K$ by our experiments, the value of $\left(K_{1} / K_{2}\right)$ can be assumed to represent the same kinetic parameter of $K$ in case of low VHP concentration. 
Table 4. Determination of the model parameter $K$ in Equation (8).

\begin{tabular}{ccc}
\hline Test material & $K\left(\mathrm{~s}^{-1}\right)$ estimated by experiment & $K\left(\mathrm{~s}^{-1}\right)$ estimated by CFD \\
\hline Stainless steel (SUS304) & $8.40 \times 10^{-3}$ & $9.20 \times 10^{-1}$ \\
Floor material (resin) & $1.72 \times 10^{-2}$ & $2.89 \times 10^{0}$ \\
Pyrex glass & $4.21 \times 10^{-3}$ & $5.87 \times 10^{-1}$ \\
Plywood & $5.81 \times 10^{-2}$ & $1.31 \times 10^{2}$ \\
Wall material (resin) & $1.17 \times 10^{-2}$ & $1.77 \times 10^{0}$ \\
\hline
\end{tabular}

The calculated value of $\left(K_{1} / K_{2}\right)$ was $2.11 \mathrm{~s}^{-1}$ for galvanized steel (21.8 ${ }^{\circ} \mathrm{C}$, Verce et al. [17]). On the other hand, $K$ estimated by CFD in this study was $0.92 \mathrm{~s}^{-1}$ for stainless steel and $2.89 \mathrm{~s}^{-1}$ for floor material (resin) $\left(22.2^{\circ} \mathrm{C}\right)$. It could be estimated that both $\left(K_{1} / K_{2}\right)$ and $K$ were approximately same orders considering the differences of materials.

\section{Application to a Three-Dimensional Model Room}

A CFD simulation coupled with the VHP transport and wall surface decomposition model was carried out for a full-sized three-dimensional model room. The purpose of this analysis was to demonstrate potential application and possibility of contribution of CFD simulation to prediction of indoor VHP concentrations at the design stage. The simulation results in this section are just the application example of the wall surface decomposition model of VHP into 3-dimensional CFD simulation and the validation of the prediction accuracy will be future study.

Figure 8 shows the target room model with dimensions of $4.25 \mathrm{~m}(x) \times 4.42 \mathrm{~m}(y) \times 3.0 \mathrm{~m}(\mathrm{z})$. The room had one supply inlet opening at the center of the ceiling and one exhaust opening at the corner of the ceiling. The floor was covered by floor material (resin) and the other wall surfaces including the ceiling were stainless steel (see Table 3 and Table 4). In this room model, a VHP generator $(0.5 \mathrm{~m}(x) \times 0.9 \mathrm{~m}(y) \times 0.4 \mathrm{~m}(\mathrm{z}))$ was located on the floor. The VHP generator had one supply inlet (from the generator to the room) at the top of the device and one exhaust outlet (from the room to the generator) on the lower part of the device. The recirculation ratio for VHP inside the VHP generator was set at $0 \%$.

Numerical and boundary conditions for the room model analyses are shown in Table 5. Steady-state CFD simulations were performed using a low Reynolds (Re) number-type $k$ - $\varepsilon$ model [23]. The value for turbulent kinetic energy at the inlet was prescribed assuming $10 \%$ turbulence intensity. A no-slip boundary condition was applied at the wall surfaces inside the room model. A second-order upwind scheme was used for the convection term and the SIMPLE algorithm was used. The geometric shapes of the wall surfaces and the VHP generator were constructed using tetra mesh. The first mesh wall surface was set within the viscous sub-layer and the wall units $\left(y^{+}\right)$met the requirement of $\leq 1.0$ over the entire surface of the room model. In addition, the total number of grid cells was set to approximately 2 million meshes based on a grid independence check.

Two representative cases were analyzed: Case 1) fundamental conditions with the wall surface decomposition model (Equation (6)) and air-conditioning ( $U_{\text {in }}=0.2 \mathrm{~m} / \mathrm{s}$ from ceiling), and Case 2 ) with the wall surface decomposition model and without air-conditioning $\left(U_{i n}=0 \mathrm{~m} / \mathrm{s}\right)$.

VHP was supplied from the VHP generator to the room model space; a constant VHP concentration $\left(C_{i n, V H P-g}\right.$ $=1.0$ ) was assumed at the inlet of the VHP generator. VHP concentration distribution analyses were performed using non-dimensional concentrations. Isothermal conditions were assumed.

The flow and VHP concentration distributions are analyzed by ANSYS/FLUENT16.

\section{Results and Discussion of the Room Model Analysis}

Figure 9 shows the flow patterns (scalar velocity distributions) within the room model. Non-uniform air flow distributions were observed for both Cases 1 and 2. In Case 1, indoor air flow was produced by the supply jet from the VHP generator and supplied air flow from the ceiling (air-conditioning system). The supplied air velocity from the ceiling $\left(U_{i n}=0.2 \mathrm{~m} / \mathrm{s}\right)$ was relatively low compared with that from the VHP generator $\left(U_{i n}=8.1\right.$ $\mathrm{m} / \mathrm{s}$ ) and hence, the air flow distributions in Cases 1 and 2 were nearly the same.

Figure 10 shows the VHP concentration distributions within the room model for the two cases analyzed. The 
Table 5. Numerical and boundary conditions for the large-scale climate chamber analysis.

\begin{tabular}{|c|c|}
\hline Turbulence model & Low-Re-type $k-\varepsilon$ model (Abe-Kondoh-Nagano model) \\
\hline Mesh & $1,913,914$ meshes (wall unit $y^{+}<1$ ) \\
\hline Scheme & Convection term: second-order upwind \\
\hline $\begin{array}{l}\text { Inflow boundary } \\
\text { (room model) }\end{array}$ & $\begin{array}{l}\text { Case 1: } U_{\text {in }}=0.2 \mathrm{~m} / \mathrm{s}, k_{\text {in }}=3 / 2\left(0.1 U_{\text {in }}\right)^{2}, \quad \varepsilon_{\text {in }}=C_{\mu}^{3 / 4} k_{\text {in }}^{3 / 2} / l_{\text {in }}, C_{\mu}=0.09, l_{\text {in }}=0.02 \mathrm{~m} \\
\text { Case 2: } U_{\text {in }}=0 \mathrm{~m} / \mathrm{s} \\
C_{\text {in }}=0\end{array}$ \\
\hline $\begin{array}{l}\text { Outflow boundary } \\
\text { (room model) }\end{array}$ & $\begin{array}{l}U_{\text {out }}=\text { free slip, } k_{\text {out }}=\text { free slip, } \varepsilon_{\text {out }}=\text { free slip } \\
C_{\text {out }}=\text { free slip }\end{array}$ \\
\hline $\begin{array}{l}\text { Inflow boundary } \\
\text { (VHP generator) }\end{array}$ & $\begin{array}{l}U_{i n}=8.1 \mathrm{~m} / \mathrm{s}, k_{i n}=3 / 2\left(0.1 U_{i n}\right)^{2}, \quad \varepsilon_{i n}=C_{\mu}^{3 / 4} k_{i n}^{3 / 2} / l_{i n}, C_{\mu}=0.09, l_{i n}=0.02 \mathrm{~m} \\
C_{i n, V H P-g}=1.0\end{array}$ \\
\hline $\begin{array}{l}\text { Outflow boundary } \\
\text { (VHP generator) }\end{array}$ & $\begin{array}{l}U_{\text {out }}=\text { free slip, } k_{\text {out }}=\text { free slip, } \varepsilon_{\text {out }}=\text { free slip } \\
C_{\text {out }, V H P-g}=\text { free slip }\end{array}$ \\
\hline Wall treatment & $\begin{array}{l}\text { Velocity, no-slip } \\
\text { VHP, deposition flux model in Equation (6) }\end{array}$ \\
\hline VHP & Passive scalar (turbulent Schmidt number $\sigma_{t}=1.0$ ) \\
\hline
\end{tabular}

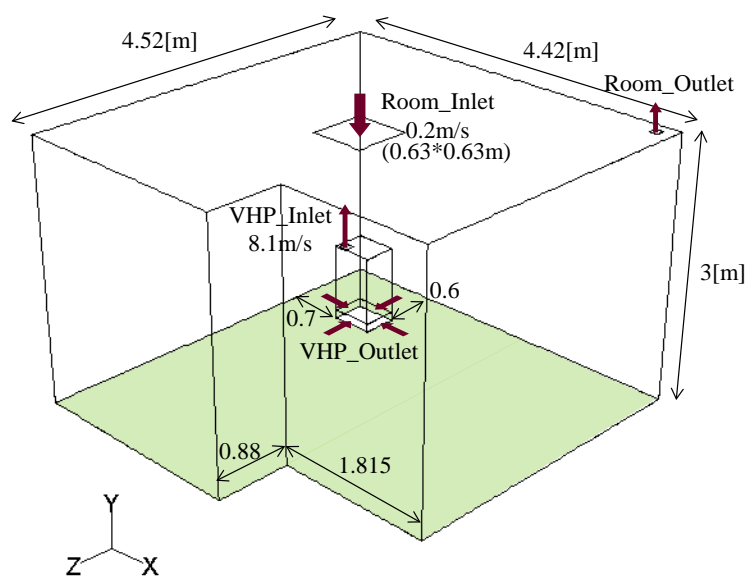

(1) Room model

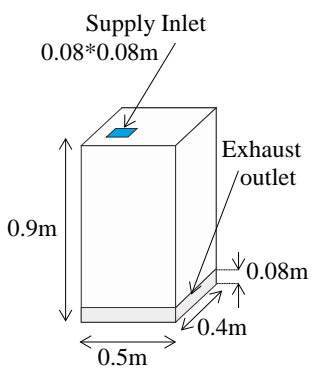

(2) VHP generator

Figure 8. Diagram of the room model and VHP generator.

VHP concentrations in Figure 10 were normalized (non-dimensionalized) by the supply inlet VHP concentration at the VHP generator $\left(C_{i n, V H P-g}\right)$ as a representative concentration.

In Case 1, clean air (0 VHP concentration air) was supplied to the room model at the ceiling and a constant VHP concentration was generated by the VHP generator. Therefore, clearly non-uniform VHP concentration distributions formed in the room model. Except for the clean air supply and wall surface decomposition, no chemical reaction models (e.g., first-order and second-order rate constant models) were incorporated into the Case 1 analysis. The volume-averaged VHP concentration in the model room was 0.48 for Case 1 . Additionally, we carried out VHP concentration distribution analysis assuming zero decomposition flux $(\gamma=0)$ and air conditioning $\left(C_{i n}=0\right)$ and the volume-averaged VHP concentration in the model room was estimated as 0.53 . This corresponds to a 5\% decrease in the VHP concentration through wall surface decomposition and a $47 \%$ decrease in the VHP concentration through ventilation.

In Case 2 with the wall surface decomposition model and without air-conditioning ( $\left.U_{i n}=0 \mathrm{~m} / \mathrm{s}\right)$, the volume-averaged VHP concentration in the model room became 0.82 , corresponding to an $18 \%$ decrease in the VHP concentration through wall surface decomposition. The decomposition flux of VHP on the wall surface was proportional to the reference indoor VHP concentration, as shown in Equation (6). Differences in the VHP concentration distributions near the wall surfaces had a strong impact on the total decomposition rate at the wall surfaces. 


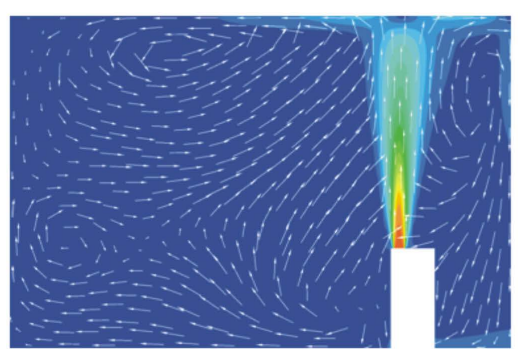

(a) $y$-z section at $x=0.7971 \mathrm{~m}$

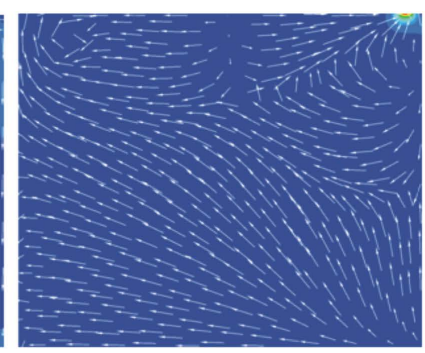

(b) $y$-z section at $x=4.235 \mathrm{~m}$

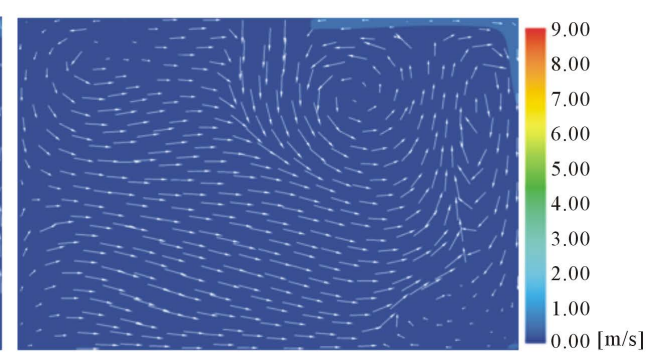

(c) $y$-z section at $x=2.21 \mathrm{~m}$

(1) Case 1 (room air-conditioning system on)

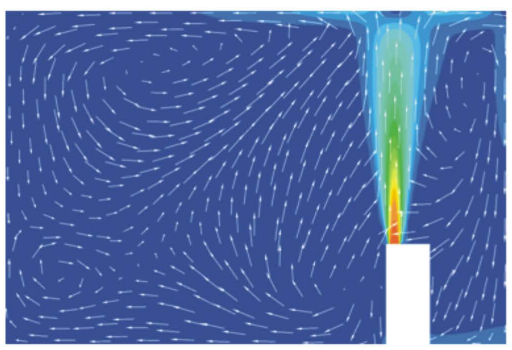

(a) $y$-z section at $x=0.7971 \mathrm{~m}$

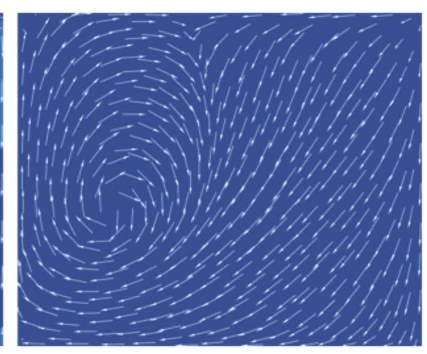

(b) $y$-z section at $x=4.235 \mathrm{~m}$

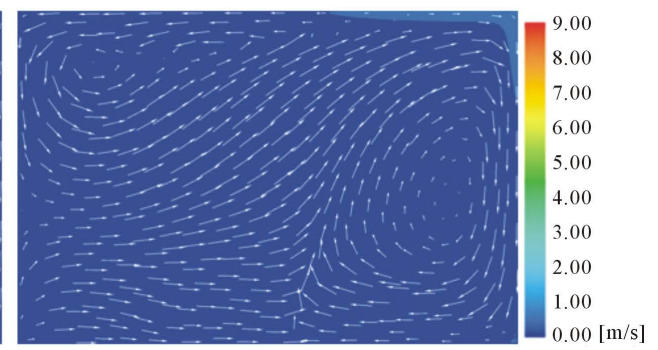

(c) $y$-z section at $x=2.21 \mathrm{~m}$

(2) Case 2 (room air-conditioning system off)

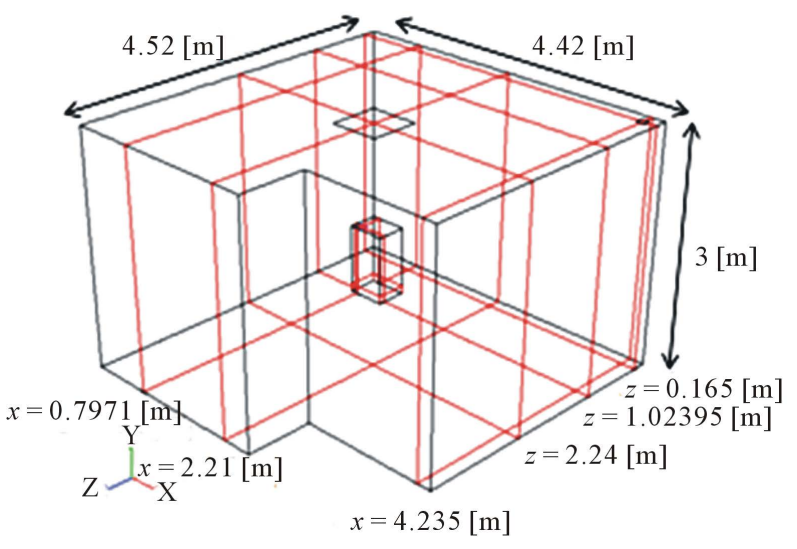

(3) Displayed sections

Figure 9. Air flow distributions in the model room determined by CFD.

The critical differences of boundary condition in Case1 and Case2 were the differences of fresh air supply from ceiling (with or without fresh air supply). In Case1, generated VHP was diluted by fresh air from ceiling and decomposed on the wall surfaces but in Case 2, generated VHP was only decomposed by wall surface decomposition (in this Case2, there was no fresh air supply).

In general, VHP concentrations in indoor sterilization are controlled by monitoring representative concentrations in the room, e.g., a point concentration at the center of the room or the concentration at the inlet of the VHP generator. However, the design concentration should be established with reference to the wall surface VHP concentration and/or the wall surface decomposition flux. The described CFD-integrated VHP wall surface decomposition model has the potential to improve prediction of wall surface concentrations and wall surface decomposition flux, leading to improvements in decontamination/sterilization efficiency with VHP.

The prediction accuracy of VHP concentration distribution analysis in indoor environment is strongly dependent on the quality of CFD simulation. We carefully conducted CFD simulation for referring previous benchmark test results [24]-[30]. Furthermore, the decomposition flux model discussed in this study is assumed to apply inside viscous sub-layer (wall unit $y^{+}<1$ ) and the first grid points adjacent to the wall were satisfied $y^{+}<1$ condition in most areas. In this point of view, the CFD procedure, boundary and numerical conditions including 


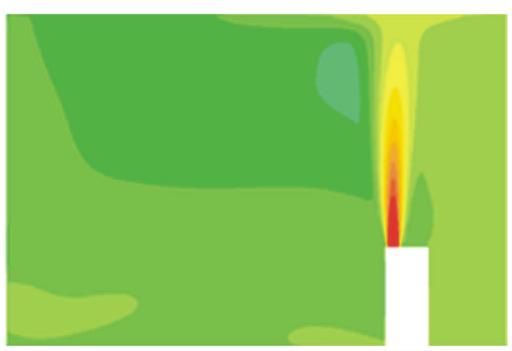

(a) $y$-z section at $x=0.7971 \mathrm{~m}$

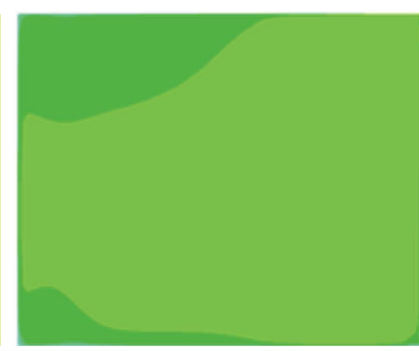

(b) $y$-z section at $x=4.235 \mathrm{~m}$

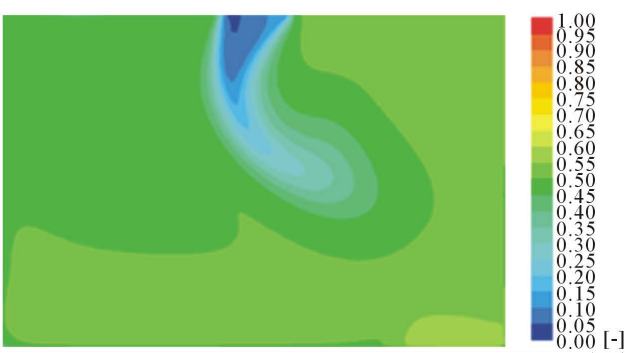

(c) $y$-z section at $x=2.21 \mathrm{~m}$

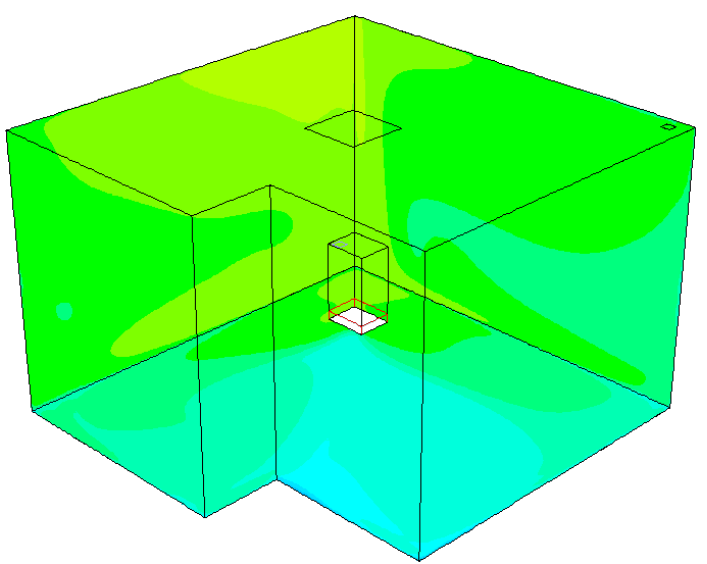

(d) Wall surface VHP concentration distributions ( $y$-z plane at $x=0, x-y$ plane at $z=0$ and floor)

(1) Case 1 (room air-conditioning system on)

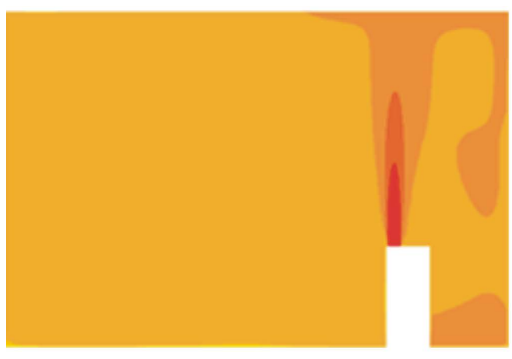

(a) $y$-z section at $x=0.7971 \mathrm{~m}$

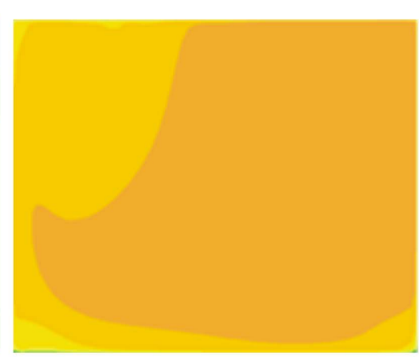

(b) $y$-z section at $x=4.235 \mathrm{~m}$

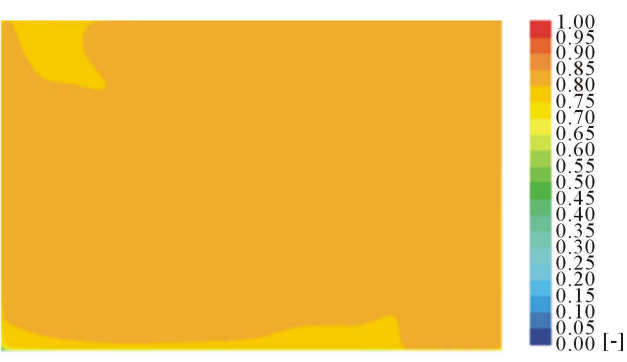

(c) $y$-z section at $x=2.21 \mathrm{~m}$

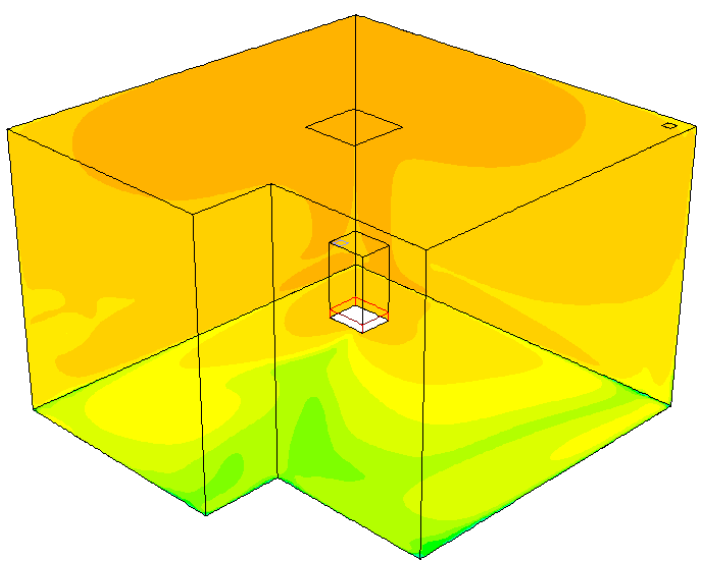

(d) Wall surface VHP concentration distributions ( $y$-z plane at $x=0, x-y$ plane at $z=0$ and floor)

(2) Case 2 (room air-conditioning system off)

\section{Figure 10. VHP concentration distributions in the room model.}


decomposition flux model parameters could be judged that there was enough rationality and accuracy. However, the prediction results of VHP concentration distribution in Figure 10 were not directly validated by experimental data and the results shown in Figure 10 just represent the results of sensitivity analyses as a function of decomposition flux model parameter.

\section{Conclusions}

In this study, we proposed two wall decomposition models for VHP and demonstrated methods for identifying model parameters using experiments with a rectangular duct chamber and CFD analysis. The findings of this study can be summarized as follows:

1) In experiments where VHP was supplied to the duct at 0.8 - $13 \mathrm{ppm}$, the concentration ratios $\left(C_{\text {out }} / C_{\text {in }}\right)$ were essentially constant for the various test materials. Therefore, wall decomposition did not show concentration dependence over the range 0.8 - 13 ppm VHP.

2) Based on the concentration ratios $\left(C_{\text {out }} / C_{\text {in }}\right)$ obtained in experiments with the rectangular duct apparatus, $\gamma$ (the VHP decomposition property for a building material) for stainless steel was approximately $2.64 \times 10^{-6}, \gamma$ for the floor material (resin) was approximately $8.25 \times 10^{-6}, \gamma$ for Pyrex glass was approximately $1.72 \times 10^{-6}, \gamma$ for plywood was approximately $1.26 \times 10^{-4}$, and $\gamma$ for the wall material (resin) was approximately $5.13 \times 10^{-6}$. We observed that $\gamma$ did not depend on the flow field, but rather on the material, because $\gamma$ was assumed to be established within the molecular diffusion region in the viscous sub-layer.

3) The smallest value of $\gamma$ was found for Pyrex glass, whereas the largest value was found for plywood, 43 times larger than that for Pyrex glass.

4) Values of the model parameter $K$ (in the source (sink) term of the decomposition model) estimated by the experimental results were approximately two orders of magnitude smaller than those identified by CFD. Thus, the value of the model parameter may have a large error if estimated using a method that does not consider the non-uniformity of the concentration field.

Typically, for evaluation of sterilization using a biological indicator, the most essential information is the relationship between the fumigation time and the concentration, specifically, the total decomposition on the sterilization surface. Therefore, wall decomposition models and the associated model parameters for various building materials provide fundamental information for sterilization using VHP.

\section{Acknowledgements}

This research was partially supported by a Grant-in-Aid for Scientific Research (JSPS KAKENHI). The authors would like to express special thanks to the funding source.

\section{References}

[1] Heckert, R.A., Best, M. and Jordan, L.T. (1997) Efficacy of Vaporized Hydrogen Peroxide against Exotic Animal Viruses. Applied and Environmental Microbiology, 63, 3916-3918.

[2] Klapes, N.A. and Vesley, D. (1990) Vapor-Phase Hydrogen Peroxide as a Surface Decontaminant and Sterilant. Applied and Environmental Microbiology, 56, 503-506.

[3] Johnston, M.D., Lawson, S. and Otter, J.A. (2005) Evaluation of Hydrogen Peroxide Vapour as a Method for the Decontamination of Surfaces Contaminated with Clostridium botulinum Spores. Journal of Microbiological Methods, 60, 403-411. http://dx.doi.org/10.1016/j.mimet.2004.10.021

[4] Murakami, S., Kato, S., Ito, K., Yamamoto, A., Kondo, Y. and Fujimura, J. (2001) Distribution of Chemical Pollutants in a Room Based on CFD Simulation Coupled with Emission/Sorption Analysis. ASHRAE Transactions, 107, 812-820.

[5] Murakami, S., Kato, S., Ito, K. and Zhu, Q. (2003) Modeling and CFD Prediction for Diffusion and Adsorption within Room with Various Adsorption Isotherms. Indoor Air, 13, 20-27. http://dx.doi.org/10.1034/j.1600-0668.13.s.6.3.x

[6] Ataka, Y., Kato, S., Murakami, S., Zhu, Q., Ito, K. and Yokota, T. (2004) Study of Effect of Adsorptive Building Material on Formaldehyde Concentrations: Development of Measuring Methods and Modeling of Adsorption Phenomena. Indoor Air, 14, 51-64. http://dx.doi.org/10.1111/j.1600-0668.2004.00316.x

[7] Ito, K. (2007) Experimental and CFD Analyses Examining Ozone Distribution in 2D Model Room with Laminar and Turbulent Flow Field. Journal of Asian Architecture and Building Engineering, 6, 387-394. http://dx.doi.org/10.3130/jaabe.6.387

[8] Bourdin, D., Mocho, P., Desauziers, V. and Plaisance, H. (2014) Formaldehyde Emission Behavior of Building Mate- 
rials: On-Site Measurements and Modeling Approach to Predict Indoor Air Pollution. Journal of Hazardous Materials, 280, 164-173. http://dx.doi.org/10.1016/j.jhazmat.2014.07.065

[9] Zhang, Q. and Zhang, G. (2007) Study on TVOCs Concentration Distribution and Evaluation of Inhaled Air Quality under a Re-Circulated Ventilation System. Building and Environment, 42, 1110-1118. http://dx.doi.org/10.1016/j.buildenv.2005.11.012

[10] Ito, K. (2008) Numerical and Experimental Analyses Examining Ozone and Limonene Distributions in Test Chamber with Various Turbulent Flow Fields. International Journal of Air-Conditioning and Refrigeration, 16, 89-99.

[11] Ito, K. and Harashima, H. (2011) Coupled CFD Analysis of Size Distributions on Indoor Secondary Organic Aerosol Derived from Ozone/Limonene Reactions. Building and Environment, 46, 711-718. http://dx.doi.org/10.1016/j.buildenv.2010.10.003

[12] Ito, K., Yagi, H. and Nishikawa, K. (2007) Numerical Modeling and Coupled CFD Analysis of Cluster Ions in Indoor Environment. ROOMVENT 2007, Helsinki, 13-15 June 2007, 129.

[13] Sørensen, D.N. and Weschler, C.J. (2002) Modeling-Gas Phase Reactions in Indoor Environments Using Computational Fluid Dynamics. Atmospheric Environment, 36, 9-18. http://dx.doi.org/10.1016/S1352-2310(01)00479-4

[14] Duran, J.E., Mohseni, M. and Taghipour, F. (2010) Modeling of Annular Reactions with Surface Reaction Using Computational Fluid Dynamics (CFD). Chemical Engineering Science, 65, 1201-1211. http://dx.doi.org/10.1016/j.ces.2009.09.075

[15] Chen, X. and Chen, Q. (2010) Comparison of Different Decontaminant Delivery Methods for Sterilizing Unoccupied Commercial Airliner Cabins. Building and Environment, 45, 2027-2034. http://dx.doi.org/10.1016/j.buildenv.2010.01.013

[16] Satterfield, C.N. and Stein, T.W. (1957) Homogeneous Decomposition of Hydrogen Peroxide Vapor. Journal of Physical Chemistry, 61, 537-540. http://dx.doi.org/10.1021/j150551a006

[17] Verce, M.F., Jayaraman, B., Ford, T.D., Fisher, S.E., Gadgil, A.J. and Carlsen, T.M. (2008) Minimizing Decomposition of Vaporized Hydrogen Peroxide for Biological Decontamination of Galvanized Steel Ducting. Environmental Science and Technology, 42, 5765-5771. http://dx.doi.org/10.1021/es702404g

[18] Aipert, S.M., Knappe, D.R.U. and Ducoste, J.J. (2010) Modeling the UV/Hydrogen Peroxide Advanced Oxidation Process Using Computational Fluid Dynamics. Water Research, 44, 1797-1808. http://dx.doi.org/10.1016/j.watres.2009.12.003

[19] Worsnop, D.R., Zahniser, M.S. and Kolb, C.E. (1989) Temperature Dependence of Mass Accommodation of $\mathrm{SO}_{2}$ and $\mathrm{H}_{2} \mathrm{O}_{2}$ on Aqueous Surfaces. The Journal of Physical Chemistry, 93, 1159-1172. http://dx.doi.org/10.1021/j100340a027

[20] Kawasaki, K., Masudome, J., Horata, H. and Oteyama, R. (2012) Bio-Decontamination Technology for a Room of Aseptic Processing Area in Pharmaceutical Plant Using Hydrogen Peroxide Vapor. Japan Air Cleaning Association, 49, 37-43. (In Japanese)

[21] Cano-Ruiz, J.A., Kong, D., Balas, R.B. and Nazaroff, W.W. (1993) Removal of Reactive Gases at Indoor Surfaces: Combining Mass Transport and Surface Kinetics. Atmospheric Environment, 27A, 2039-2050. http://dx.doi.org/10.1016/0960-1686(93)90276-5

[22] Ito, K., Sørensen, D.N. and Weschler, C.J. (2005) Measurements of Mass Accommodation Coefficients Using a Flat-Plate Test Chamber. Indoor Air 2005, 10th International Conference on Indoor Air Quality and Climate, Beijing, 4-9 September 2005, 2335-2339.

[23] Abe, K., Kondoh, T. and Nagano, Y. (1994) A New Turbulence Model for Predicting Fluid Flow and Heat Transfer in Separating and Reattaching Flows-I. Flow Field Calculations. International Journal of Heat and Mass Transfer, 37, 139-151. http://dx.doi.org/10.1016/0017-9310(94)90168-6

[24] Ito, K., Inthavong, K., Kurabuchi, T., Ueda, T., Endo, T., Omori, T., Ono, H., Kato, S., Sakai, K., Suwa, Y., Matsumoto, H., Yoshino, H., Zhang, W. and Tu, J. (2015) CFD Benchmark Tests for Indoor Environmental Problems: Part 1 Isothermal/Non-Isothermal Flow in 2D and 3D Room Model. International Journal of Architectural Engineering Technology, 2, 1-22.

[25] Ito, K., Inthavong, K., Kurabuchi, T., Ueda, T., Endo, T., Omori, T., Ono, H., Kato, S., Sakai, K., Suwa, Y., Matsumoto, H., Yoshino, H., Zhang, W. and Tu, J. (2015) CFD Benchmark Tests for Indoor Environmental Problems: Part 2 Cross-Ventilation Airflows and Floor Heating Systems. International Journal of Architectural Engineering Technology, 2, 23-49. http://dx.doi.org/10.15377/2409-9821.2015.02.01.2

[26] Ito, K., Inthavong, K., Kurabuchi, T., Ueda, T., Endo, T., Omori, T., Ono, H., Kato, S., Sakai, K., Suwa, Y., Matsumoto, H., Yoshino, H., Zhang, W. and Tu, J. (2015) CFD Benchmark Tests for Indoor Environmental Problems: Part 3 Numerical Thermal Manikins. International Journal of Architectural Engineering Technology, 2, 50-75. http://dx.doi.org/10.15377/2409-9821.2015.02.01.3

[27] Ito, K., Inthavong, K., Kurabuchi, T., Ueda, T., Endo, T., Omori, T., Ono, H., Kato, S., Sakai, K., Suwa, Y., Matsumo- 
to, H., Yoshino, H., Zhang, W. and Tu, J. (2015) CFD Benchmark Tests for Indoor Environmental Problems: Part 4 Air-Conditioning Airflows, Residential Kitchen Airflows and Fire-Induced Flow. International Journal of Architectural Engineering Technology, 2, 76-102. http://dx.doi.org/10.15377/2409-9821.2015.02.01.4

[28] Sørensen, D.N. and Nielsen, P.V. (2003) Quality Control of Computational Fluid Dynamics in Indoor Environments. Indoor Air, 13, 2-17. http://dx.doi.org/10.1111/j.1600-0668.2003.00170.x

[29] Zhai, Z., Zhang, Z., Zhang, W. and Chen, Q. (2007) Evaluation of Various Turbulence Models in Predicting Air-Flow and Environments by CFD: Part 1-Summary of Prevalent Turbulence Models. HVAC\&R Research, 13, 853-870. http://dx.doi.org/10.1080/10789669.2007.10391459

[30] Zhang, Z., Zhang, W., Zhai, Z. and Chen, Q. (2007) Evaluation of Various Turbulence Models in Predicting Airflow and Turbulence in Enclosed Environments by CFD: Part-2: Comparison with Experimental Data from Literature. HVAC\&R Research, 13, 871-886. http://dx.doi.org/10.1080/10789669.2007.10391460

\section{Nomenclature}

$C$ : VHP concentration (ppm)

$C_{i}$ : pollutant concentration reacting with VHP in the air (ppm)

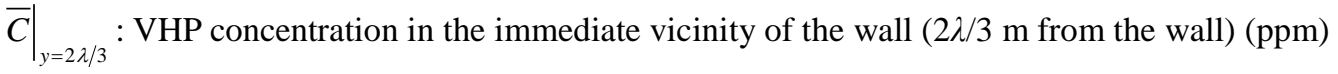

$\left.\bar{C}\right|_{y=\Delta y_{1}}:$ VHP concentration at the discretely defined point (ppm)

$D$ : molecular diffusion coefficient of VHP $\left(\mathrm{m}^{2} / \mathrm{s}\right)$

$J_{d}$ : decomposition flux of VHP in the immediate vicinity of the wall

$k_{b}$ : second-order reaction rate constant for the reaction between VHP and microorganisms in the air $\left(\mathrm{ppm}^{-1} \cdot \mathrm{s}^{-1}\right)$

$k_{u}$ : first-order reaction rate constant for self-attenuation $\left(\mathrm{s}^{-1}\right)$

$K$ : model coefficient

$K_{1}$ : model coefficient

$K_{2}$ : model coefficient

$r_{1}$ : amount of VHP that is removed from the air after it collides with the wall surface

$r_{2}$ : total amount of VHP that collides with the wall surface.

$S_{b}$ : loss of $C$ through the intermolecular reaction between VHP and the pollution in the air (ppm/s)

$S_{u}$ : loss of $C$ through the first-order reaction (self-attenuation) of VHP in the air (ppm/s)

$U_{j}$ : ensemble-mean velocity component $(\mathrm{m} / \mathrm{s})$

$u^{*}$ : friction velocity

$\langle v>$ : average thermal velocity of VHP $(\mathrm{m} / \mathrm{s})$

$v_{d}$ : deposition velocity $(\mathrm{m} / \mathrm{s})$

$y^{+}:$wall unit

$\Delta y_{1}$ : distance of the defined point from the wall (m)

$\gamma$ : reaction probability (decrease in the rate of VHP colliding with the wall surface)

$v_{t}$ : turbulent eddy viscosity $\left(\mathrm{m}^{2} / \mathrm{s}\right)$

$\rho$ : the air density $\left(\mathrm{kg} / \mathrm{m}^{3}\right)$

$\sigma_{t}$ : turbulent Schmidt number

$\tau_{w}$ : the wall shear stress 